\title{
An Interpretation of Plato's Ideas and Criticism of Parmenides according to Peano's Ideography
}

\author{
By Giuseppe Boscarino*
}

\begin{abstract}
Anyone who studies the Platonic work finds great difficulty in interpreting the precise meaning of his ontological terms, which are most often enveloped in an obscure and mystical language. Aristotle already emphasized the allegorical and poetic meaning of the platonic terms "imitation" and "participation," related to the sensible things, "copies" of the "ideas." I have asked myself then the following question: Is there a rational and logical nucleus within the mystical and mythological shell of Platonism? Studying the mathematical ideography of Peano, a great logician, mathematician and contemporary linguist, elicited the following question: can we make an ideographic translation of Plato's ontological terms in the same way Peano did for aspects of Euclid's work? We demonstrate a possible valid, rational, and logical nucleus of certain Platonic nomenclature beyond the mists of certain metaphysical interpretation, while also showing Plato's criticism of Parmenides to be invalid in the light of Peano's ideography.
\end{abstract}

\section{Difficulty in the Interpretation of Platonic Theory in Educational and Historiographical Processes}

Many students have experienced the darkness, ambiguity and vagueness of philosophical language in the study of the history of philosophy. This turns into difficulty whenever the teacher has to explain to young students the thoughts of a philosopher, using the most limpid and clear language possible. Thus, texts on the history of philosophy instead of helping young people to escape from imprecise, vague and primitive ways of reasoning, rather accentuate this aspect, exposing the thinking of philosophers in even more obscure and ambiguous ways than seen in the original source.

We live this experience in particular in the teaching and daily work of philosophical and epistemological research, striving to achieve the formation and evolution of concepts and conceptions of the world, without making the absurd and ahistorical distinction between history of philosophy and history of science.

After the study of the so-called period of "Presocratics," which usually are made to look like illogical and stuttering children, we pass to the study of Platonic philosophy.

The teacher or scholar, in absence of a precise definition of Plato's idea, tries his best to facilitate the understanding of his students. The texts do not help and indeed confuse and entangle things more; thus, young people

\footnotetext{
* President, Cultural Association, The Italic School, Italy.
} 
remain hesitant and confused when they are interrogated about the which concepts they have grasped.

Respected Italian texts written by authoritative historians of philosophy give the most varied definitions of Plato' idea.

1. The Ideas are not simple concepts, that is purely mental representations, but they are "entities," "substances;"1

2. The Platonic idea is therefore the only and perfect model of the multiplicity of imperfect things of this world. In our world there is a plurality of things more or less Beautiful or Righteous, but in the world of ideas there is the Beauty or the Justice; ${ }^{2}$

3. For each variety of sensible things designated by the same name or similar one in shape we must therefore assume an entity in itself that constitutes of it the essence or pure form or unity; so that the ideas can be said to be real as such. ${ }^{3}$

Faced with these propositions, if one tries to analyze the logical and rational content, it remains confused and bewildered, because the content itself is often meaningless, unclear, tautological, or vague.

If we went then to the direct reading of Plato and even some authoritative scholar of Platonic philosophy in the hope that it could help us in trying to understand whether "some rational and logical core" were present in the "mystical and obscure shell" of Platonic thought, we still would not escape from the mystical and vague cloud of concepts.

If we try to read "Plato and the theory of ideas" 4 it soon becomes clear that not only does Ross not clarify the issue, but also that in some passages of his book he presents glaring contradictions in Platonic writings as progress in the evolution of the doctrine of ideas. The Ross writes that, ${ }^{5}$

There is a passage of Hippias (major) that seems to bear witness to a development of the theory of Ideas [...]. This passage is interesting in two respects; first of all because it prefigures the issue raised in Parmenides, namely whether there is the Idea as a whole or just part of it to be possessed by the individual things that fall in the very idea, and then because it reveals an interest that occupied Plato in the last stage of his existence.

1. Giovanni Reale, and Dario Antiseri, Philosophy in its Historical Development, vol. 1. (Brescia: La Scuola, 1995).

2. Nicola Abbagnano, and Giovanni Fornero, Philosophers and Philosophies in History, vol. 1. (Torino: Paravia, 1999), 180.

3. Gabriele Giannantoni, The Philosophical Research: History and Texts, vol. 1. (Torino: Loescher, 1992).

4. David Ross, Platone e la teoria delle idee (Plato and the Theory of Ideas) (Bologna: Il Mulino, 1989), 41-42.

5. Ibid. 
Compare it with the Platonic passage quoted by him,

Socrates: "Anyway, tell me again: each of us is it one, and happens it to him to be one?"
"Hippias: Of course!"
Socrates: "Then, if is it one, each of us is it also odd. Do not think you that one is odd?"
"Hippias: Yes"
Socrates: "But being two, are we two together also odd?"
Hippias: "Impossible, Socrates!"
Socrates: "Then are we both together even, even is also each of us individually?"
Hippias: "Obviously not!"
Socrates: "It is therefore not at all necessary as well as you asserted just now that we in
two should be that we are alone and that we should be individually that we are in
two.

Here clearly Socrates (or Plato) committed two errors: the first is coarse, as he exchanges those that are properties of numbers, the second one is of a logicallinguistic nature, because it confuses the logical product " 1 is an odd number and 1 is an odd number $=1$ and 1 are odd" with the arithmetic operation " 1 and $1=1+$ $1=2 . "$

There are some scholars who deny the Platonic authorship of the dialogue Hippias major, considering it spurious; and indeed, some historians of mathematics deem that the first mistake can be taken as a proof of this thesis (not noticing the second one), since Plato, who is considered a scholar of mathematics according to tradition, could not incur so coarse an oversight. In fact, they overlook the fact that the same mistake, although in more veiled way, is located in the Phaedo of Platonic.

Thus mistrusting even the authoritative interpreters of clear and established fame, I decided to limit myself to the reinterpretation of Plato's dialogues, in the hope of being able to give an answer to a question that had now become only mine, a scholar of logic and epistemology.

The re-reading of Plato did not solve my problem. Plato's language is very imprecise, vague and mythological; the various translations make things worse, as different authors often translate differently the same passages.

Luckily, my reading of Peano's works showed me a way to solve my problem. The logical rigor and impeccable, linguistic precision of his writings yield great admiration and esteem. His ideographic method allows us to study complex and delicate logical-epistemological questions. Meanwhile, I have tried to better define my problem: Is there a rational and logical nucleus inside the mystical and mythological shell of Platonism?

6. Plato, The Dialogues of Plato translated into English with Analyses and Introductions by B. Jowett, M.A. in Five Volumes. 3rd edition revised and corrected (London: Oxford University Press, 1892). Retrieved from goo.gl/CSZRMH. 
After reading Peano, ${ }^{7}$ in an effort to answer this problem, my question became: Can we make an ideographic translation of Platonic conceptions in the same way that Peano did with the work of Euclid?

\section{Ideas, Models and Copies in Platonic Thought: An Ideographic Interpretation}

Anyone who studies the Platonic work finds a great difficulty in interpreting the precise meaning of his terms, which are usually wrapped in dark and mysterious language. Aristotle already emphasized the allegorical and poetic meaning of the Platonic terms "imitation" and "participation" by referring to things in relationship to "ideas."

I started from the hypothesis that beyond the mystical, religious, metaphysical and controversial meanings, Platonism had a rational and logical kernel, and that its philosophical nomenclature could be decoded with logical formal language, using, in part, Peano's ideographic symbols.

The Platonic terms often have a strong intuitive and emotional content. Only if they are precisely defined, are we be able to explain their logical and rational content. Let us thus analyze the following important passages from Plato's Phaedon where Socrates, before his death, is committed to demonstrating through anamnesis (or remembrance) the immortality of soul.

Socrates argues that man is in possession of knowledge, which cannot draw its origin from sensible knowledge. This is the case of the idea "the equal" ( $\tau \dot{o} \iota \sigma o v)$; the sensible things equals $(\tau \dot{\alpha} \iota / \sigma \alpha)$ imitate, part of the idea of "the equal" or this is present (parousia) in them. "The equal" is the "model" of the sensible equals. Thus, Socrates speaks with the other authors of the dialogue:

And shall we proceed a step further, and affirm that there is such a thing as equality, not of one piece of wood or stone with another, but that, over and above this, there is absolute equality? Shall we say so? Say so, yes, replied Simmias, and swear to it, with all the confidence in life. And do we know the nature of this absolute essence? To be sure, he said. Well; and may you not also from seeing the picture of a horse or a lyre remember a man? and from the picture of Simmias, you may be led to remember Cebes; True. Or you may also be led to the recollection of Simmias himself? And in all these cases, the recollection may be derived from things either like or unlike? It may be. And when the recollection is derived from like things, then another consideration is sure to arise, which is-whether the likeness in any degree falls short or not of that which is recollected? Very true, he said. The imperfect equality of pieces of wood or stone suggests the perfect idea of equality. And shall we proceed a step further, and affirm that there is such a thing as equality, not of one piece of wood or stone with another, but that, over and above this,

7. Giuseppe Peano, Opere, I, II, III (Roma: Cremonese, 1957); Peano, Formulario mathematico (Form mathematician) (Roma: Cremonese, 1960). 
there is absolute equality? Shall we say so? Say so, yes, replied Simmias, and swear to it, with all the confidence in life. And do we know the nature of this absolute essence? And do we know the nature of this absolute essence? To be sure, he said. And whence did we obtain our knowledge? Did we not see equalities of material things, such as pieces of wood and stones, and gather from them the idea of an equality which is different from them? For you will acknowledge that there is a difference. Or look at the matter in another way: Do not the same pieces of wood or stone appear at one time equal, and at another time unequal? That is certain. But are real equals ever unequal? or is the idea of equality the same as of inequality? Impossible, Socrates. Then these (so-called) equals are not the same with the idea of equality? I should say, clearly not, Socrates. And yet from these equals, although differing from the idea of equality, you conceived and attained that idea? Very true, he said ... Well, he said, then I should like to know whether you agree with me in the next step; for I cannot help thinking, if there be anything beautiful other than absolute beauty should there be such, that it can be beautiful only in so far as it partakes of absolute beauty - and I should say the same of everything. Do you agree in this notion of the cause? Yes, he said, I agree. All things exist by participation in general ideas. He proceeded: I know nothing and can understand nothing of any other of those wise causes which are alleged; and if a person says to me that the bloom of colour, or form, or any such thing is a source of beauty, I leave all that, which is only confusing to me, and simply and singly, and perhaps foolishly, hold and am assured in my own mind that nothing makes a thing beautiful but the presence and participation of beauty in whatever way or manner obtained; for as to the manner I am uncertain, but I stoutly contend that by beauty all beautiful things become beautiful. This appears to me to be the safest answer which I can give, either to myself or to another, and to this I cling, in the persuasion that this principle will never be overthrown, and that to myself or to anyone who asks the question, I may safely reply, That by beauty beautiful things become beautiful. Do you not agree with me? ... First of all assume that there is an absolute beauty and goodness and greatness, and the like; grant me this, and I hope to be able to show you the nature of the cause, and to prove the immortality of the soul. ${ }^{8}$

These platonic, ambiguous and unintelligible passages, left with only their immediate and intuitive meaning, provoke a strong mystical pathos. What does it mean "the equal" or "the equal to itself?" What are equals? When are two individuals equal? What does it mean that equal individuals take part or are in communion with "equals?" What does it mean that "the equal to itself" is the "model" and that equal individuals are their "copies?" If nothing is defined, everything is ambiguous, obscure and mystical.

Only if these things are defined and we try to interpret the Platonic philosophical nomenclature, can these things acquire their rational and logical nucleus, which may be communicable, understandable, and therefore questionable. Without these requirements, the reader's mind, especially if the reader is a young student, becomes confused and deceived. In this setting, his rational and critical abilities do not develop and becomes only an automatic repeater, rather than an analyzer.

8. Plato, The Dialogues of Plato translated into English. 
Let us try rather to formalize the material, using in part Peano's ideography. We can say that two individuals, $x$ and $y$, are equal if and only if the following applies:

$$
\mathrm{x}=\mathrm{y}:=\forall \mathrm{P}[\mathrm{P}(\mathrm{y}) \leftrightarrow \mathrm{P}(\mathrm{x})]
$$

(Let us read: two individuals are said by definition to be equal $(:=)$ if every $(\forall)$ property $(\mathrm{P})$ which applies to the individual $\mathrm{x}$ also applies to $\mathrm{y}$ and vice versa.)

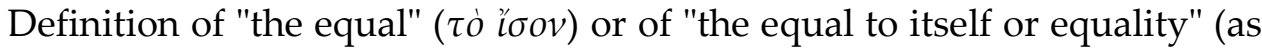
it is translated, $\alpha \hat{v} \tau \dot{o} \tau \dot{o} \iota \sigma o v)$.

(Please note that Plato indifferently uses the logical-linguistic operators $\tau \dot{o}$ or

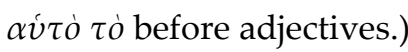

$$
\mathrm{tx}:=\mathrm{y} \ni(\mathrm{y}=\mathrm{x})
$$

(Let us read: The class equal to $x$ is constituted by all thosey such that $(\exists) \mathrm{y}$ is equal to $x$, where the equal is defined by 1 . The class of equals $\mathrm{x}(\mathrm{t}$ is the initial word of the Greek iota, $\left.\iota^{\circ} \sigma \mathrm{v}\right)$, the symbol used for the first time by Peano to define the class with a single element) is the class with just one element $x$; in the Platonic nomenclature this class is the idea of equal or the equal.)

Notice how in the Platonic nomenclature to before the adjective assumes the meaning of logical and linguistic operator that makes possible the passage from the individual to the class with a single element, the Singleton, as one might call the Platonic idea today. Plato, however, does not conceive the idea (or singletons) in extensional terms, that is of something set with only one element, but rather in intensional terms, that is of something with many properties, which are fulfilled by one and only one individual. So if in 2 , we replace the 1 , this becomes:

$$
\mathrm{xx}:=\mathrm{y} \exists\{\forall \mathrm{P}[\mathrm{P}(\mathrm{y}) \leftrightarrow \mathrm{P}(\mathrm{x})]\}
$$

(Let us read: the equals to $\mathrm{x}$ are all those $\mathrm{y}$ that have all and only the same properties as $\mathrm{x}$; these properties cannot be met if not only by the $\mathrm{x}$, that is such properties constitute the idea of $x$.)

If we operate on 3 with $y \epsilon$ (y belongs), we get,

$$
y \in \text { ix. : }=\forall P[P(y) \leftrightarrow P(x)]
$$

(Let us read: $y$ is one of the equals to $x$ or $y$ belongs to the equals to $x$, or, if you want to use the ambiguous Platonic language, $y$ takes part of the equals to $x$. In the Platonic language, we still could say " $x$ is the model," and y is the "copy" of it. Because it participates, it is an element of "the equal," of "the equal as identical," of "the idea of the equal.") 
What has been said for "the equal and equals," also applies to the beautiful, and beautiful things, to the right and right things, etc. It has in fact " $b_{x}=x$ is beautiful." Then we have,

$$
\begin{aligned}
& \mathrm{b}_{\mathrm{x}}=\mathrm{b}_{\mathrm{y}}:=, \forall \mathrm{P}\left[\mathrm{P}\left(\mathrm{b}_{\mathrm{x}}\right) \leftrightarrow \mathrm{P}\left(\mathrm{b}_{\mathrm{y}}\right)\right] \\
& \mathrm{b}_{\mathrm{x}}:=\mathrm{b}_{\mathrm{y}} \exists\left(\mathrm{b}_{\mathrm{y}}=\mathrm{b}_{\mathrm{x}}\right) \\
& \mathrm{b}_{\mathrm{x}}:=\mathrm{b}_{\mathrm{y}} \exists\left\{\forall \mathrm{P}\left[\mathrm{P}\left(b_{y}\right) \leftrightarrow \mathrm{P}\left(b_{x}\right)\right]\right\} \\
& \mathrm{b}_{\mathrm{y}} \in \mathrm{t} \mathrm{b}_{\mathrm{x}}:=\forall \mathrm{P}\left[\mathrm{P}\left(\mathrm{b}_{\mathrm{y}}\right) \leftrightarrow \mathrm{P}\left(\mathrm{b}_{\mathrm{x}}\right)\right]
\end{aligned}
$$

Here is a possible rational and logical nucleus of certain Platonic philosophical nomenclature, beyond the mists of some usual metaphysical interpretation; it is simple and straightforward when expressed in formal logical terms. This rational nucleus, like Aristotle himself testifies, comes from the Pythagoreanism professed by Plato, although it was wrapped in this cloud of mysticism connected to the Orphic tradition and his philosophical conception.

\section{The Ideal Number and the Mathematical Number in Plato and the Pythagoreans}

On the conception of the number two in both the Platonic and the Pythagorean traditions, the sources of thought are confused because of their difficult interpretation, almost all of which are Platonic or neo-Platonic, Aristotelian or neo-Aristotelian tradition. Few enlightening testimonies remain in this regard.

Sharing the judgment of the great mathematician and logician Peano, according to whom Plato's works yield very little mathematically rigorous content, ${ }^{9}$ and considering the Neo-Platonist Proclus Lycaeus (412-485 AD) maximally unreliable, we can only turn to the testimony of the same disciple of Plato, namely Aristotle, who thus writes on the conception of the number in Plato and the Pythagoreans:

The name "participation" was new; for the Pythagoreans say that things exist by "imitation" of numbers, and Plato says they exist by participation, changing the name. But what the participation or the imitation of the Forms could be they left an open question. Further, besides sensible things and Forms he says there are the objects of mathematics, which occupy an

9. Giuseppe Peano, Opere, Vol. III (Roma: Cremonese, 1958), 249. For a harsh judgement about Plato, witness of mathematical things, I recall a judgement of Peano, who certainly knew about mathematics, as with Greek philology: Untrue in the philosopher's dialogues there are some mathematical terms here and there, but reunited in such an uncertain way that they were considered as difficult words which an interlocutor looks for to confuse his adversary; almost like in our political newspapers of today "incommensurable" is written instead of "very big." 
intermediate position, differing from sensible things in being eternal and unchangeable, from Forms in that there are many alike, while the Form itself is in each case unique. ... so is his view (Plato, ours) that the Numbers exist apart from sensible things, while they (Phithagoreans, ours) say that the things themselves are Numbers, and do not place the objects of mathematics between Forms and sensible things. His divergence from the Pythagoreans in making the One and the Numbers separate from things, and his introduction of the Forms, were due to his inquiries in the region of definitions. ${ }^{10}$

The Pythagoreans, also, believe in one kind of number-the mathematical; only they say it is not separate but sensible substances are formed out of it. For they construct the whole universe out of numbers-only not numbers consisting of abstract units; they suppose the units to have spatial magnitude. ${ }^{11}$

From these Aristotelian witnesses expressed in an obscure, ambiguous and vague language, profound differences emerge between the philosophy of Plato and the Pythagorean one about the number and the concept of reality:

1. For the Pythagoreans numbers are not separated from their magnitudes; the numbers are logos between magnitudes, homogeneous to a magnitude taken as unit of measure. Plato instead separates the numbers from magnitudes and assigns them a separate and real existence, independent from magnitudes.

2. For the Pythagoreans there is only one type of number, the mathematical number, such as logos, ratio, reason, law. For Plato, beyond the mathematical number, there is the ideal number. It is between the sensible world and the intelligible world of ideas; it is eternal and immovable, like ideas, but it is multifaceted as a sensible thing, while every ideal form is itself unique and individual. (How to say that over the many $2 \mathrm{~s}$, which indicate two objects, that is, 2 pears, 2 apples, etc., there is the idea of 2, 12 , which is one and individual, while the other, as it is predicated is multifaceted.)

3. For the Pythagoreans the number 2 is mathematical, because it is the relationship between physical objects that we count or measure after being idealized. It is abstracted from our physical operations of counting and measuring, from which it draws its meaning and its purely logicalnominal existence. Physical objects, for which the magnitudes precede the numbers, exist only as ideas of physical properties, namely as 12; saying with Plato that they exist as ideas, so $\exists\llcorner 2$, it is to reify the idea of physical properties, 12 , in its name, which is the only individual extension of the idea $\mathbf{2}$.

10. Metaphysics by Aristotle, written 350 B.C.E., translated by W. D. Ross, Book I. Retrieved from goo.gl/hF35k.

11. Ibid., Book XIII. 
The philosophy of Plato about the existence of the idea of numbers as names therefore becomes:

1. A purely nominalistic philosophy, having evaporated the physical properties that the Pythagorean philosophy wants to maintain, making reference to the existence of mathematical number, for the existence of mere names. Plato to escape the aporia about the meaning of existence of the number, puts it in hyperuranium, in other words in heaven, which we cannot see, remaining the pure faith in its existence in another world! The philosophical and scientific research of rational and empirical natures thus die in this great idealistic confusion establishing faith in the existence of ideas, because we no longer know what they are. This is the case on the rational plane and on the physical plane, which no longer refer to physical properties, but to mere names.

2. Plato so conceives three distinct degrees of reality in a hierarchy: at the top the world of ideas, the ineffable; in the bottom, the sensible vulgar world; in the middle, the mathematical world, with its beings who do not need to understand the sensible world. It is not helpful to understand the sensible world, which does not deserve special attention; the mathematical world only serves to remind the world of hyperuranium of absolute perfection.

In the philosophy of the Italics, from which Plato detaches, the sensible world is mere appearance, just chaos, whereas the true reality coincides with our rational reconstruction, carried out through logical and mathematical procedures.

Therefore, the numbers, as relations between magnitudes, are reality itself. Besides these relations there is no and there cannot be anything but shapeless and changing sensations, about which nothing can be said unless one is singing the dark odes of Heraclitus' philosophy, according to which everything changes.

3. For Plato numbers exist before the act of thinking, not in the same way as ideas, given the uniqueness of these. For the Pythagoreans, as already said, numbers are obtained by abstraction from magnitudes and from physical things. Plato's goal is to unclip numbers from magnitudes and then from physical knowledge.

Even for Aristotle, numbers are obtained by abstraction, but they, like other mathematical entities, do not serve to make physical science. ${ }^{12}$

12. Giuseppe Boscarino, Tradizioni di pensiero. La tradizione di pensiero italica della scienza e della realtà (Traditions of thought. The tradition of Italic thought of science and reality) (Roma: Aracne, 2016); Boscarino, Le forme e i mutamenti della scienza. Tradizioni di pensiero, ideologie e conflitto sociale (The forms and changes of science. Traditions of thought, ideologies and 
This is the common position of Plato and Aristotle in mathematics and its relationship with physics. It is precisely this point that marks the deep gap between the Pythagoreans on the one hand, supporting the unity of thought and being, and on the other hand Plato and Aristotle, who support the multiplicity of worlds (trino or bina that it is), in short between the two traditions of thought.

\section{An Interpretation of Peano's Ideography of Parmenides' Texts: Being and Nothing $(\Lambda)$, and Existing $(\exists)$}

In indicating the two ways that reason follows in the path of research, Parmenides says in one of his famous fragments: ${ }^{13}$

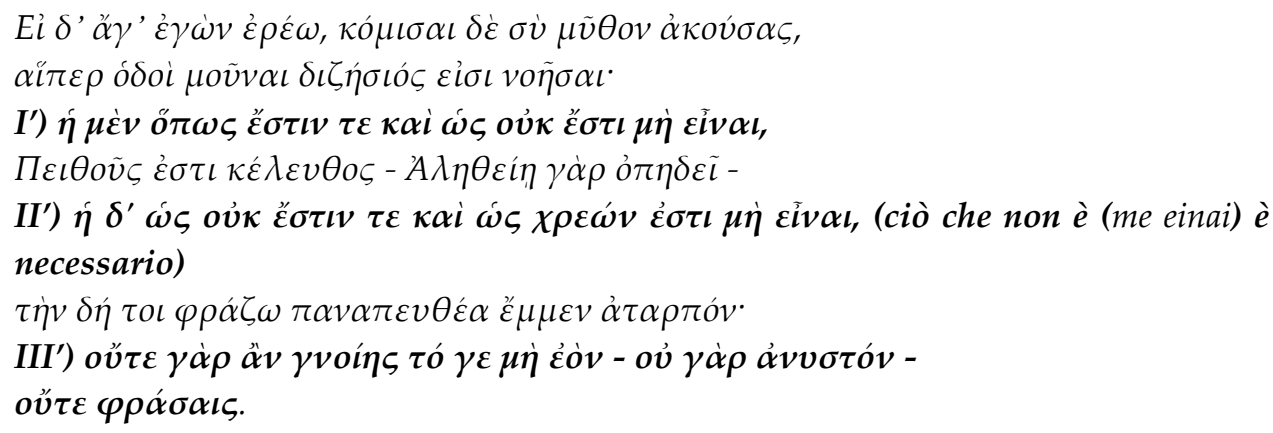

Come now, I will tell thee and do thou hearken to my saying and carry it away - the only two ways of search that can be thought of. I') The first, namely, that It is, and that it is impossible for anything not to be, is the way of conviction, for truth is its companion. II') The other, namely, that It is not, and that something must needs not be, - that, I tell thee, is a wholly untrustworthy path. III') For you cannot know what is not - that is impossible - nor utter it; ${ }^{14}$

Let us translate now into symbols the three propositions, whereby $\mathrm{P}$ indicates some property. The first follows thus:

$$
\left.I^{\prime}\right) P \text { is }:=\exists P:=P \neq \Lambda
$$

(This proposition expressed in words, which are close to the sense of Parmenides' proposition, means: If for some property we say it is, thereby we mean that the property exists, or else it is not an empty, absurd, or contradictory property)

social conflict) (Roma: Aracne, 2016); Boscarino, The mystery of Archimedes. The tradition of Italic thought of science (Roma: Aracne, 2017).

13. Mario Untersteiner, Sofisti: testimonianze e frammenti (Sophists: testimonies and fragments) (Firenze: La Nuova Italia, 2009), 128-130;

14. Retrieved form goo.gl/Zmae3w. 
II') $\mathrm{P}$ is not $:=\neg \exists \mathrm{P}:=\mathrm{P} \neq \Lambda$

(This proposition means: If for some property we say it is not, this means $\mathrm{P}$ does not exist and $\mathrm{P}$ is not absurd. However, it is not possible to follow this line of research, for it is absurd, because of what we say it does not exist, it is not possible to say it is not contradictory, or is possible it is, or even that it has some individuals, because otherwise we would affirm the following proposition, (III'), from which its absurdity seems clear, because not being can neither be thought nor be expressed.)

If the first path is in fact the true one, but we wanted to consider nothing as something thinkable or speakable, we should have then,

$$
\text { III') } \Lambda \text { is }:=\exists \Lambda:=\Lambda \neq \Lambda
$$

But something cannot be other than itself, even if it is nothing, because you can neither think of nothing nor can you say it!

\section{Inconsistent Criticism from Plato about Being and Nothing $(\Lambda)$, and Existing ( $\exists$ ) to Parmenides: About Plato's Famous Patricide}

Plato's criticisms of Parmenides have two objectives:

1. Parmenides saying that nothing cannot be thought of or said is in contradiction with himself as he speaks of it, and certainly thinks of it, as in (III').

2. Nothing can be said and thought of, if not as a relative nothing to some property, such as in the case "not to be" even numbers = odd, where Not to be is understood as different, and therefore different from even numbers, which as such they are or are not absurd. Thus, we can say there is Not to be, unlike what Parmenides says in (II').

In symbols,

$$
\text { IV) it is not } \mathrm{P}:=\neg \mathrm{P} \neq \Lambda:=\exists \neg \mathrm{P}
$$

As regards the first criticism, see Plato, The Sophist, 237. In these passages Plato helps us understand that the Parmenidean nothing, $\Lambda$, can be neither thought of nor said without contradicting itself. In fact, we would have according to our previous formula:

$$
\text { III') } \Lambda \text { is }:=\exists \Lambda:=\Lambda \neq \Lambda \quad \text { Def. }
$$


If Plato refers in his speech to nothing, $\Lambda$, he says a correct thing, but if he wants to refer to the idea of nothingness, $\mathrm{\Lambda} \Lambda$, he would say an incorrect thing, because asserting the following formula is not contradictory:

$$
\left.\mathrm{IIII}^{\prime \prime}\right) \iota \text { is }:=\exists\llcorner\Lambda:=\iota \Lambda \neq \Lambda
$$

That is, that idea of nothingness exists or that nothing is something. We can therefore talk about nothing and think of it, but understood as an idea of the name, such as $\mathrm{\Lambda} \Lambda$, without contradicting itself.

However, Parmenides' prohibition is not this, nor in this case Plato makes against Parmenides' principle. Not saying and not thinking about nothing of Parmenides refers to the empty class, $\Lambda$, and not to its idea or its name, $\Lambda$, as Plato interprets it.

It concerns the III', not the III", as the III' is contradictory, which claims to affirm that nothing is a $\tau \iota$, a certain thing, or a being.

The absurd ideas, or rather their names, do exist but do not correspond to any individual of which they are names. It is this second case to which Parmenides refers. Plato, only making a mess, thinks of refuting Parmenides. However, this remains unrefuted, so Parmenides can safely think and talk of nothing, as the idea of the name, without contradicting itself.

The second criticism concerns Plato's famous patricide against Parmenides.

STRANGER: You will promise not to regard me as a parricide.

THEAETETUS: And why?

STRANGER: Because, in self defence, I must test the philosophy of my father Parmenides, and try to prove by main force that in a certain sense not being is, and that being, on the other hand, is not. ${ }^{15}$

The famous patricide of Plato was born again from a sophisticated confusion of Plato about the commutative property between the logical existence operator, $\exists$, and the logical negation operator, not, in symbol. $\neg$.

If $\mathrm{P}$ is a class or property, then,

$\neg \exists \mathrm{P} \neq \exists \neg \mathrm{P}$

In the left part of inequality it is stated that P class is empty, it has not individuals, in the right part it is stated that the complementary of $\mathrm{P}$ class, i.e., $P$ is not empty, has individuals. For example, we can say: There are not even numbers, which would be false, as well. There are even numbers = odd exist, and that would be true. The two propositions have different meanings, we cannot refute one by affirming the truth of the other, as with Plato's Parmenides.

15. E. A. Duke, W. F. Hicken, W. S. M. Nicoll, D. B. Robinson, and J. C. G. Strachan, Platonis Opera, vol. 1, Tetralogias I-II (New York: Oxford Univeristy Press, 1995), 397. 
The two logical operators do not compute. For Parmenides the following logic identity is valid,

1. $\mathrm{P}=\Lambda:=\neg \exists \mathrm{P}$

For Plato instead the following logic identity is valid,

2. $\neg \mathrm{P} \neq \Lambda:=\exists \neg \mathrm{P}$

As we see, Plato never makes a patricide, arguing against Parmenides that

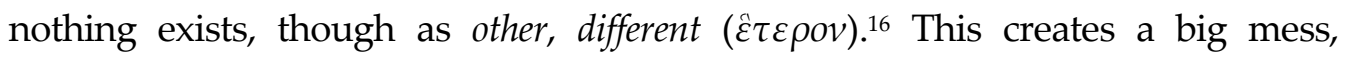
because when Parmenides speaks of nothing he refers to (1), while Plato tries to refute it with (2)!

\section{Conclusion}

To conclude, as the science of Archimedean, Galilean and Newtonian tradition works. Not in the Platonic sense, on a supposed science of generic ideas, mere mental representations, confused entities or metaphysical substances or on unspecified models, but on simple and obvious properties, abstract from the world of sensitive observation, conceived in themselves, as ideas of properties, or elements, related to other ideas of property, by definitions or axioms, assumed as principles, from which mathematical calculus deduces the consequences, which are then verified or falsified through concrete models, with precise rules of correspondence in the experimental field. ${ }^{17}$

Instead I would like to conclude with what an excellent physicist, mathematician, enlightened philosopher, but also an acute epistemologist, D'Alembert, wrote at his time about a supposed science of ideas, certainly thinking of the decanted "divine" Plato.

"Thus, even though I might inadvertently shock some people whose zeal for Metaphysics is more fervent than enlightened, I shall take care not to define it according to their wishes as the science of ideas. For what would such a science be? Philosophy, whatever its object, is either the science of facts or the science of chimeras. Indeed it would be a vague and quite inaccurate idea about Philosophy to believe it destined to lose itself in abstractions, in the general properties of a being, in the general properties of mode and substance. Such useless speculation consists only of presenting in scientific form and language propositions expressed in ordinary language, and these propositions could be nothing more than either accepted truth that would be embarrassing to display with such fanfare or at the very least questionable, and consequently unworthy of being proposed as

16. Ibid., 423.

17. Boscarino, Tradizioni di pensiero. 
principles. Besides, such a method is not only dangerous because it impedes by vague and contentious questions the progress of our true knowledge, it is also contrary to the way the mind works. For we cannot repeat too often that we are able to know abstractions only by studying the particulars. Therefore the first thing we must undertake in good Philosophy is to rid ourselves of those long, boring prolegomena, those eternal nomenclatures, those endless trees and divisions, all sad remnants of unfortunate scholasticism and ignorant vanity of those dark ages which, devoid of facts and observations, created for themselves an imaginary subject of speculation and disputes. ${ }^{18}$

\section{Acknowledgements}

The author wishes to express his gratitude and appreciation to Prof. Armando Anzaldo for his assistance and advice about the English translation.

\section{Bibliography}

Abbagnano, Nicola, and Fornero, Giovanni. Philosophers and Philosophies in History, vol. 1. Torino: Paravia, 1999.

Boscarino, Giuseppe. Tradizioni di pensiero. La tradizione di pensiero italica della scienza e della realtà (Traditions of thought. The tradition of Italic thought of science and reality). Roma: Aracne, 2016.

Boscarino, Giuseppe. Le forme e i mutamenti della scienza. Tradizioni di pensiero, ideologie e conflitto sociale (The forms and changes of science. Traditions of thought, ideologies and social conflict). Roma: Aracne, 2016.

Boscarino, Giuseppe. The mystery of Archimedes. The tradition of Italic thought of science. Roma: Aracne, 2017.

d'Alembert, Jean-Baptiste le Rond, and de La Chapelle, Jean. "Elements of the Sciences," The Encyclopedia of Diderot E d'Alembert Collaborative Translation Project. Translated by Lauren Yoder. Ann Arbor: Michigan Publishing, Univeristy of Michigan Library, 2011. [Originally published as "Elemens des Sciences," Encyclopédie ou Dictionnaire raisonné des sciences, des arts et des métiers, 5:491-497 (Paris, 1755)]

18. Jean-Baptiste le Rond d'Alembert, and Jean de La Chapelle, "Elements of the Sciences," The Encyclopedia of Diderot \& d'Alembert Collaborative Translation Project, trans. Lauren Yoder (Ann Arbor: Michigan Publishing, Univeristy of Michigan Library, 2011). [Originally published as "Elemens des Sciences," Encyclopédie ou Dictionnaire raisonné des sciences, des arts et des métiers, 5:491-497 (Paris, 1755)] 
Duke, E. A., Hicken, W. F., Nicoll, W. S. M., Robinson, D. B., and Strachan, J. C. G. Platonis Opera, vol. 1, Tetralogias I-II. New York: Oxford Univeristy Press, 1995.

Giannantoni, Gabriele. The Philosophical Research: History and Texts, vol. 1. Torino: Loescher, 1992.

Peano, Giuseppe. Opere, I, II, III. Roma: Cremonese, 1957.

Peano, Giuseppe. Formulario mathematico (Form mathematician). Roma: Cremonese, 1960.

Peano, Giuseppe. Opere, Vol. III. Roma: Cremonese, 1958.

Plato. The Dialogues of Plato translated into English with Analyses and Introductions by B. Jowett, M.A. in Five Volumes. 3rd edition revised and corrected. London: Oxford University Press, 1892. Retrieved from goo.gl/CSZRMH.

Reale, Giovanni, and Antiseri, Dario. Philosophy in its Historical Development, vol. 1. Brescia: La Scuola, 1995.

Ross, David. Platone e la teoria delle idee (Plato and the Theory of Ideas). Bologna: Il Mulino, 1989.

Untersteiner, Mario. Sofisti: testimonianze e frammenti (Sophists: testimonies and fragments). Firenze: La Nuova Italia, 2009. 
